\title{
СЛЕДЫ ЭКСПОНЕНТОВ КЛАССА В ИМЕННЫХ ОСНОВАХ ЗАПАДНОЛЕЗГИНСКИХ И ШАХДАГСКИХ ЯЗЫКОВ
}

\section{TRACES OF CLASS EXPONENTS IN THE NOMINAL BASES OF WEST LEZGIAN AND SHAHDAG LANGUAGES}

\section{Ibragimova}

Summary: The article formulates General provisions resulting from the analysis of traces of class exponents in the nominal bases of the West Lezgian and Shahdag languages. Based on the analysis of the actual material, General and specific features are revealed, which are manifested in the structure of nouns and numerals of the studied languages when fossilized class markers are isolated. About the formation of the category of nominal class in the two language groups on the relative single chronological level shows a homogeneous material base of the fossilized class markers and the small number of binary series versus Budukh and Kryz languages - Rutul and Tsakhur.

Keywords: West Lezgian languages, Shahdag languages, class category, fossilized class markers.
Ибрагимова Мариза Оглановна

Д.филол.н., дочент, в.н.С., ИЯЛИ ДФИЦ РАН (2. Махачкала) mariza71@mail.ru

Аннотация: В статье формулируются общие положения, явившиеся результатом анализа следов экспонентов класса в именных основах шахдагских и западнолезгинских языков. На основе анализа фактического материала выявлены общие и специфические особенности, проявляющиеся в структуре имен существительных и числительных исследуемых языков при вычленении окаменелых классных маркеров. 0 становлении категории именного класса в двух группах языков на относительно едином хронологическом уровне свидетельствуют однородная материальная база окаменелых маркеров класса и малочисленность бинарных рядов, противопоставляющих будухский и крызский языки рутульскому и цахурскому.

Ключевые западнолезгинские языки, шахдагские языки, категория класса, окаменелые маркеры класса.
2 ападнолезгинские и шахдагские языки относятся к лезгинской группе нахско-дагестанской языковой семьи. Рутульский и цахурский языки, объединяемые кавказоведами в западнолезгинскую подгруппу, локализованы в Рутульском районе Республики Дагестан и на сопредельных территориях Азербайджана. Будухский и крызский языки, составляющие южнолезгинскую (шахдагскую) подгруппу, локализованы в Республике Азербайджан.

Изучение исследовательских работ, содержащих описание категории класса в западнолезгинских и шахдагских языках; сравнительное описание отдельных грамматических категорий лезгинских языков двух родственных подгрупп, систематизация и анализ окаменелых экспонентов класса, пережиточно сохранившихся в именных основах будухского, крызского, рутульского и цахурского языков; выявление ареальных и типологических истоков маркеров класса методами и приемами сравнительно-исторического языкознания поможет уточнить диахронические сценарии, влияющие на степень родства исследуемых языков.

Исследователи-кавказоведы выделяют во всех четырех языках четырехклассные грамматические системы. Распределение существительных, обозначающих разумных существ, по I и II классам в сравниваемых языках мотивировано, отнесение названий птиц, насекомых и вещей к III или IV грамматическому классу не всегда семантически обусловлено.

В основах имён существительных и числительных, согласно мнению исследователей дагестанских языков М.Е. Алексеева [2003, с. 204-205], А.А. Магометова [1970, с. 48], С.М. Махмудовой [2001, с. 11], У.А. Мейлановой [1964], Ш.М. Саадиева [1970, с. 333] и др., на диахроническом уровне выявляются следы экспонентов класса.

Специфика именных классов, выявляемых посредством вычленения соответствующих окаменелых экспонентов, заключается в их функционировании вне числовой парадигмы. Значимость окаменелых классных маркеров, выявляемых в структуре имён, усиливается, согласно С.М. Хайдакову, тем, что «Классы, сформировавшиеся без учета грамматического числа, по нашему мнению, имеют большую хронологическую глубину, чем классы, функционирующие на основе бинарных числовых форм» [1980, с. 66].

Как правило, окаменелые маркеры классов занимают анлаутную позицию. Для верификации их наличия в структуре существительных привлекают диалектный материал или когнаты из родственных языков. В качестве реконструируемых в структуре имен существительных классных маркеров дагестановеды выделяют $\partial, p, \breve{u}, \mathrm{H}$, л, 6, в, м, 21, Әж [Магометов, 1970, с. 48; Хайдаков, 1980, 
с. 120], С.М. Хайдаков квалифицирует их в синхронном плане как элементы «расширенного корня» [1980, с. 120].

Наименее частотными из них в исследуемых языках являются дж, реконструируемый только в крызском языке, м (не входящий в систему маркеров на синхронном уровне) и л, статус которого лингвисты трактуют неоднозначно. Так, Ш.М. Саадиев, приводя примеры из крызского языка с суффиксальным согласным л: 'т1ыл «палец», къил «нога», сил «зуб», г1уьл «глаз», бел «лоб», кьыл «голова», миаьл «нос»', отмечает, что «... функционально $\underline{л}$ ничего общего не имеет ни с классными показателями, ни с обычными словообразующими суффиксами. Вероятно, он является лишь детерминативным показателем, по которому в крызском языке группируются названия частей тела» [Саадиев, 1970, с. 340].

С.М. Хайдаков полагал, что окаменелые классные экспоненты и в ауслауте существительных - названий жидких и сыпучих тел одновременно являлись и показателями множественного числа, что позволило ему выдвинуть гипотезу о выражении анлаутными классными маркерами одного предмета, а ауслаутными - двух и более, т.е. о совмещении семантики грамматического числа, которая формировалась в лезгинских языках в рамках категории именного класса. [Хайдаков, 1980, с. 121].

С.М. Махмудова доказывает наличие отголосков грамматических классов в рутульском языке примерами согласования имен с глаголами: «виригь в-иъи «солнце/ есть/», кьул в-иъи, выш й-иъи, рыш р-иъи, ваз в-иъи, йукъуд й-иъи, йывыд й-иъи, выгын в-иъи и т.д.» [2001, с. 11]. В примерах мы-тыл «козленок» (рут.) - тил (будух.), мугул «метла» (рут.) - кул «веник» (лезг.) С.М. Махмудова усматривает наличие в рутульском языке окаменелого классного показателя м, восходящего к пралезгинскому хронологическому уровню [Там же]. Нечастотный окаменелый экспонент класса м в структуре агульских существительных выделяет А.А. Магометов [1970, с. 48], в структуре крызских существительных - Ш.М. Саадиев [1970, с. 333].

Среди именных частей речи в западнолезгинских и шахдагских языков особняком стоят имена прилагательные, не сохранившие классную дифференциацию в полной мере. Как правило, они не располагают классными показателями, в связи с чем не обладают формальными словоизменительными признаками, и поэтому отношения между предметом и его признаком выражаются не с помощью согласования, то есть уподобления форм зависимого слова формам главенствующего компонента, как это происходит в языках с атрибутивным согласованием, а с помощью примыкания.

Ш.М. Саадиев прослеживает в ряде прилагательных крызского языка инфиксальные классные маркеры (джек. су-р-кьур «спелый», су-б-кьур, су-д-кьур; хап.су-ркьурд «спелый», су-б-кьурд, су-д-кьурдж и т. д.), отмечая, что они «... со временем затушевывались» [1970, с. 483].

В мухадском диалекте, лежащем в основе формируемого литературного рутульского языка, как правило, в структуре прилагательных не выявляются классные маркеры, за исключением некоторых лексем с инфиксальными классными показателями:

І кл. - ч1у-ø-куд «кривой», II кл. - 41у-р-укуд, III кл. -

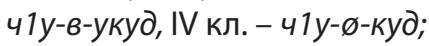

І кл. - гьа-р-хыд «высокий», I| кл. - гьа-р-хыд, III кл. гьа-б-хыд, IV кл. - гьа-д-хыд;

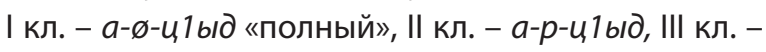

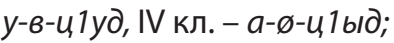

| кл. - хъи-б-кьыд «спелый», || кл. - хъи-р-икьыд, ||| кл. - хъи-в-икьыд, IV кл. - хъи-ø-кьыІд.

Согласно гипотезе лингвистов-кавказоведов об увязывании возможности выделения классного маркера в имени с его отглагольным происхождением, прилагательные, в структуре которых выявляются маркеры класса, в исследуемых языках, вероятно, имеют глагольную природу. [Алексеев, 1986, с. 132].

Ихрекский диалект рутульского языка проявляет своеобразие в грамматическом оформлении прилагательных, сохраняя префиксально-инфиксальные маркеры классов: й-эдаьды «больной» (І кл.), р-едаьды «больная» (II кл.), в-едаьды «больной/-ая/-ое» (III кл.), й-эдаьд «больной/-ая/-ое» (IV кл.), в котором прилагательные первых трех классов противопоставлены прилагательным IV класса согласовательными маркерами -ды и -д соответственно, вследствие чего формы I и IV классов й-эдаьды «больной» и й-эдаьд «больной/-ая/-е» противопоставлены и наличием/ отсутствием финального гласного -ы. Подобное противопоставление согласовательных маркеров I-III классов маркеру IV ранее мы наблюдали при описании крызского языка, оно прослеживается и в цахурском языке.

В цахурском языке дифференцированно отражается соотнесенность прилагательных с семантическим классом субстантива посредством занимающих анлаутную или инлаутную позицию классных маркеров: ык1арна адамий «больной мужчина» (І кл.), й-ик1арна хьунашше «больная женщина (II кл.), в-ук1арна балкан «больная лошадь» (III кл.), ык1аран къел «больная нога» (IV кл.). Согласно сведениям, приведенным в монографии «Цахурский язык», второй тип классного согласования «... характерен для ограниченного числа прилагательных» [Ибрагимов, 1990, с. 89].

Таким образом, в исследуемых языках прилагательные в атрибутивной функции, за редким исключением, не располагают классными показателями. Отсутствие 
формальных словоизменительных признаков обусловило выражение отношений между предметом и его признаком не с помощью согласования форм зависимого и главенствующего компонентов, а путем примыкания. В структуре некоторых прилагательных рутульского, цахурского и крызского языков пережиточно сохранились инфиксальные классные показатели. В цахурском языке и ихрекском диалекте рутульского языка в структуре некоторых прилагательных выявляются префиксальные маркеры класса.

Наличие в структуре субстантивов только окаменелых маркеров класса С.М. Хайдаков считает следствием процесса утраты признаков целостной системы категорией именного класса, имеющей одинаковую хронологическую глубину с категорией морфологического класca $[1980$, c. 120].

Сравнение диалектного материала отдельных языков также позволяет предположить наличие следов классных маркеров в именах существительных и числительных. Рассмотрим это положение на примере межъязыковых когнатов, в которых окаменелые маркеры класса либо аналогичны, либо вариативны.

В следующих именах существительных шахдагских и западнолезгинских языков выявляется единый окаменелый экспонент класса:

буд., крыз., цах. д-их «сын» - рут. д-ух;

буд., крыз., рут. й-из «снег» - цах. й-ыз;

буд. й-ыкl «сердце» - крыз. й-икl - рут. й-икl - цах. ŭ-ukl;

буд., крыз. махар «грудь» - рут. м-ыхыр - цах. муху «сосок» (ср. таб. м-ухур, лезг. хур);

буд. м-огул «метла, веник» - крыз. м-агул - рут. м-угул - цах. могул (ср. таб. м-ургул - лезг. ккул).

В ряду противопоставлений - буд. л-иш «вошь», крыз. л-иш, рут. л-ихь, цах. в-ихь - в трёх языках из четырех встречается окаменелый маркер л, выявляемый и в структуре глагола исследуемых языков в качестве классного маркера с низкой частотностью.

В приведенных ниже примерах выявляется противопоставление в основах имен существительных маркера p будухского, крызского и рутульского языков экспоненту й в цахурском языке:

буд., крыз. $p$-ux «дорога» - рут. $p$-alxъ - цах. й-alxъ; буд. $p$-ехъ «пепел» - крыз. раьхъ - рут. $p$-ы1хъ - цах. ŭ-ы1xъ;

буд., крыз. p-иш «девочка, девушка, дочь» - рут. р-ылш-цах. й-ыш

буд. шиди-р «сестра» - крыз. шиды- $p$ - рут. $p$-иши цах. й-ичи

Согласно Ш. М. Саадиеву, «... в крызских существи- тельных ши-д «брат» и ши-д-р «сестра» (ср. джем-ш-ид «шурин, деверь», джам-ши-д-р «свояченица, золовка»), наряду с корневым согласным ш, выявляются и суффиксальные классные показатели д, $\underline{p}$, которые в настоящее время окаменели» [1970, с. 333].

Противопоставление окаменелых маркеров будухского, крызского и рутульского языков экспоненту цахурского языка выявляется и в следующих примерах:

ъ/p: цах. б-акка «дверь» - буд., крыз. р-аьк - рут. $p$-ак (ср. лезг. $p$ - $а к) ;$

в/ø: цах. в-ук1ул «голова» - буд., крыз. ø-кьыл - рут. ø-кьул; цах. в-ухьун «живот» - буд., крыз. ø-фан рут. ø-ухьун;

в/л: цах. в-ихь «вошь» - буд., крыз. л-иш, рут. л-ихь.

Противопоставление единого окаменелого маркера будухского, рутульского и цахурского языков экспоненту крызского языка выявляется в следующих когнатах:

ø/м: крыз. ø-джири - буд. м-ич1ер «борода» - рут. м-ич1ри - цах. м-ыч1ры (ср. лезг. ø-ччуру);

м/в: крыз. м-иг1илаьд «самец» - буд. в-ули «самец» - рут. в-ыг1ылды «мужчина, самец» - цах. в-ыг 1 ыл «мужчина, самец».

Противопоставление единого окаменелого маркера м- крызского, рутульского и цахурского языков экспоненту будухского языка й- мы выявили в одном примере: й/м: буд. й-умур «похоронные носилки» - крыз. м-ыгыыр - рут. м-ыгыыр - цах.: м-ыгра.

Бинарные ряды окаменелых маркеров противопоставляют шахдагские языки западнолезгинским:

й/ø: буд., крыз. й-ит «мёд» - рут. ø-uт - цах. ø-итв; буд., крыз. й-еч «яблоко» - рут., цах. ø-эч; 21/ø: буд. 21-уьл «глаз» - крыз. 21-уьл - рут. ø-ул цах. ø-ул'.

Однородная материальная база окаменелых маркеров класса и малочисленность противопоставленных бинарных рядов в двух группах языков позволяют заключить, что становление в них категории именного класса происходило не автономно, а на едином хронологическом уровне.

В плане сравнения интересна лексема «солнце»: в некоторых дагестанских языках она имеет два окаменелых классных маркера: префиксальный в- (p-, б-, б-) и инфиксальный - $p$ - (-н-): буд., крыз. в-и-р-агъ «солнце»- рут. в-и- $p$-игъ - цах. в-u-p-ыгъ (ср. лезг., агул. $p$-агъ - таб. $p$-егъ - авар. б-акъ - хин. (ъ)-ы-н-кь). В частности, Ш.М. Саадиев выделял два окаменелых экспонента класса в крызском существительном «ви-ра-гъ “солнце"» [1970, с. 334].

Сравнительный анализ структуры когнатов указывает на наличие двух реликтовых экспонентов класса в язы- 
ках с четырехклассной системой и одного окаменелого маркера в языках с количеством классов три и менее.

Междиалектные когнаты также верифицируют положение о наличии окаменелых классных маркеров. Так, в основах имен существительных в диалектах рутульского языка выявляются бинарные и тернарные ряды экспонентов класса ø/в, в/й/2ь:

мух. д. ø-кьул «голова» - ихр. д. вы-кьыл;

мух. д. в-ыш «ночь» - ихр. д. й-уьш-борч.-хн. д. гь-уш.

Мнения дагестановедов о признании окаменелыми классными маркерами анлаутных показателей числительных дагестанских языков расходятся. М. Е. Алексеев отмечает, что «во-первых, числительное как атрибутивная часть речи вполне могло включать в свою основу такой показатель; во-вторых, анлаут большинства числительных имеет очевидные параллели в системе классных экспонентов ... в третьих, отмечаются реликтовые классные формы числительного 'четыре': анд. в-, й-, б-, р-окъогъу» [Алексеев, 2003, с. 220].

К.Ш. Микаилов полагает, что даже в языках с развитой системой класса, числительные не имеют анлаутных классных маркеров, связывая это с непоследовательным проявлением (наличием/ отсутствием) в разных числительных окаменелых экспонентов класса. «Утверждать, что в лице начальных согласных й, р, м д, б, в ... следует усматривать реликты категории грамматических классов, некогда выражавшейся префиксально в дагестанских именах числительных, по крайней мере, рано, хотя это возможно» $[1969$, с. 144$]$.

При установлении статуса анлаутных консонантных показателей возникают гипотезы отнесения их к результатам закономерных звукосоответствий. Аргументами для подтверждения грамматического статуса исследуемых единиц (д, p, й, н, л, б, в, м, 21, Әж) являются, во-первых, их функционирование в системе классных маркеров дагестанских языков на синхронном уровне или возможность развития их из других маркеров в результате фонетических процессов, во-вторых, согласно мнению М.Е. Алексеева, «даже и при закономерности соответствий начальных согласных они (анлаутные консонантные показатели - М.И.) вполне могут быть окаменелыми формантами» [1986, с.131].

Полагаем, что числительные шахдагских и западнолезгинских языков представляют особый интерес для верификации случаев сохранения в исследуемых языках окаменелых классных маркеров. Доказательством чего служат многочисленные факты соответствий в исследуемых языках анлаутных (в редких случаях - инлаутных) консонантных экспонентов, традиционно относимых к маркерам класса в дагестанских языках, которые уживаются в основе числительных с ауслаутными маркерами класса й/p/ в(б)/д:

p/ŭ: буд., крыз., рут. $p$-ыхьылд «шесть»- цах.й-ыхьылд; в/ й/ гь: буд. в-ич/uд «девять» - крыз. й-ичид - рут. гь-учlуд - цах. й-учlуд;

й/ (ø): буд., крыз., рут. й-укьуд «четыре» - цах. й-окьуд (ср. лезг. Ф-кьуд)

буд., крыз., рут., цах. й-иц1ыд «десять» (ср. лезг. ø-ц1уд).

Интересна структура числительного «восемь», в основе которого неоднократно выявляются следы классных маркеров:

- в анлауте выявляется нечастотный окаменелый

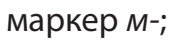

- в инлаутной позиции - противопоставленные элементы $\breve{~ / ~} 21 /$ л, которые исследователями характеризуются как экспоненты класса;

- в ауслауте I класса выявляется традиционный маркер -p, III класса - маркер -б, IV класса - маркер -д. В структуре числительного «восемь» ауслаутный классный маркер - I, // классов един для будухского, рутульского и цахурского языков, в крызском языке совпадает маркер II и III классов -б: буд. M-ы-

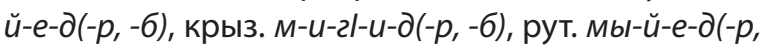
-б), цах. м-о-л-у-д(-p, -б) «восемь».

Случаи выявления следов классных экспонентов в анлауте и инлауте одновременно с функционирующими на синхронном уровне маркерами класса в ауслауте единичны и касаются только двух числительных: «семь» и «восемь» (у остальных числительных в инлаутной позиции выявляется шумный согласный).

Таким образом, в исследуемых языках представлены именные основы с одним или двумя (в структуре имен числительных) застывшими экспонентами класса, именные основы с маркерами класса, которые могут быть однородными или разнородными (окаменелыми или функционирующими на синхронном уровне) и отражать разные диахронические уровни их функционирования в языках.

Материальное совпадение в сравниваемых языках (и в дагестанских языках вообще) анлаутных согласных, квалифицируемых в кавказоведении как окаменелые классные маркеры, с функционирующими в этих языках префиксами класса позволяет аргументировано говорить о наличии в структуре имен существительных классных экспонентов на прадагестанском хронологическом уровне.

Сравнительный анализ позволил выявить вариативность окаменелых классных маркеров в основах имен существительных и числительных будухского, крызского, рутульского и цахурского языков, носящую системный характер и проявляющуюся на межъязыковом и 
внутриязыковом (междиалектном) уровнях.

Список условных сокращений: агул. - агульский язык, анд. - андийский язык, буд. - будухский язык, борч.-хн. д. борчинско-хновский диалект рутульского языка, джек. д. - джекский диалект крызского языка, ихр. д. - ихрекский диалект рутульского языка, крыз. - крызский язык, лез. лезгинский язык, мух. д. - мухадский диалект рутульского языка, мюхр. д. - мюхрекский диалект рутульского языка, рут. - рутульский язык, таб. - табасаранский язык, хин. хиналугский язык, хап. - хапутлинский диалект крызского языка, цах. - цахурский язык, I, II, III, IV - номер класса.

\section{ЛИТЕРАТУРА}

1. Алексеев М.Е. 0 методике сравнительно-исторических исследований (на материале дагестанских языков)// Актуальные проблемы дагестанско-нахского языкознания. - Махачкала, 1986. С. 114-143.

2. Алексеев М.Е. Сравнительно-историческая морфология нахско-дагестанских языков. Категории имени. - М.: Academia, 2003. 264 с.

3. Ибрагимов Г.Х. Цахурский язык. - М.: Наука, 1990. 239 с.

4. Магометов А.А. Агульский язык. Тбилиси: Мецниереба, 1970. 242с.

5. Махмудова С.М. Морфология рутульского языка. - М.: Советский писатель, 2001. 256 с.

6. Мейланова У.А. Об отражении категории класса в именах существительных дагестанских языков// Ученые записки ИИЯЛ Дагестанского филиала АН СССР. - Махачкала, 1964. Т. 13.

7. Микаилов К.Ш. К вопросу о морфологической структуре количественных имен числительных в дагестанских языках // Материалы Первой сессии по сравнительно-историческому изучению иберийско-кавказских языков. - Махачкала, 1969. С. 142-155.

8. Саадиев Ш.М. Опыт исследования крызского языка: в 2-х т.: диссертация ... доктора филологических наук: 10.00.00. - Баку, 1970. - 726 с. + Прил. (426 с.: ил.). Филологические науки. ОD Дд 73-10/46.

9. Хайдаков С.М. Принципы именной классификации в дагестанских языках. - М.: Наука. 1980. 251 с.

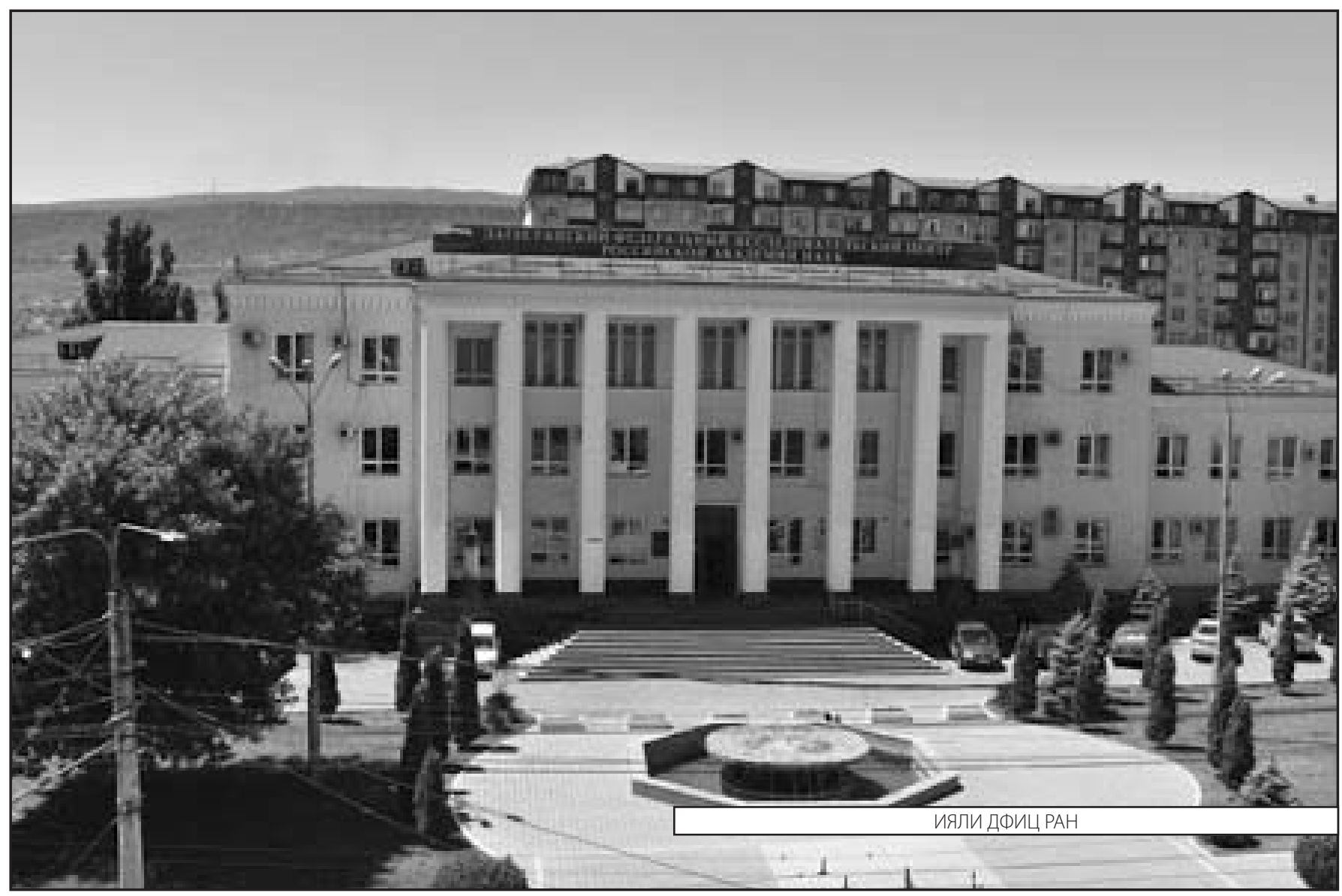

